\title{
Impact of Beta Blockers on Left Ventricular Reverse Remodeling Following Primary Coronary Intervention for ST-elevation Myocardial Infarction
}

Toshiharu Fujii', Hirofumi Nagamatsu', Manabu Kimura', Masataka Nakano1, Yohei Ohno', Gaku Nakazawa1, Norihiko Shinozaki ${ }^{1}$, Fuminobu Yoshimachi ${ }^{1}$, Yuji Ikari ${ }^{1}$

\section{Abstract}

Background: Benefits of beta-adrenergic receptor blockers (BB) following ST-elevation myocardial infarction (STEMI) are based on data before primary percutaneous coronary intervention (PCI) became the therapeutic first choice. This study examined the relationship between $\mathrm{BB}$ dose and magnitude of left ventricular ejection fraction (LVEF) improvement in STEMI following primary PCI.

Methods and Findings: A total of 235 STEMI patients following primary $\mathrm{PCl}$ who underwent echocardiography during the acute phase and over 6 months from onset were studied retrospectively. Serial LVEFs were assessed for three groups: no BB $(n=33)$, carvedilol $(n=163)$, and bisoprolol $(n=42)$. Left ventricular reverse remodeling (RR) was defined as LVEF improvement $\geq 10 \%$. All patients received fixed doses of $\mathrm{BB}$ and renin-angiotensin system inhibitor during observation. The median interval between echocardiographs was 526 days. The mean LVEF change was $+2.6 \%$ (acute: $53.9 \pm 9.9 \%$, chronic: $56.4 \pm 10.6 \%$ ). Carvedilol and bisoprolol groups showed LVEF improvement, but none was seen in the no BB group $(+3.7 \pm 6.5 \%,+3.8 \pm 6.9 \%,-4.2 \pm 5.0 \%$, $P<0.0001$, respectively). The LVEF improvement effect was $B B$ dose dependent. Therapy with BBs had a high rate of RR (no BB 0\%, carvedilol $19.4 \%$, bisoprolol $16.7 \%, P=0.0225$, respectively). Multivariate analysis showed the following predictors of RR: baseline LVEF $<50 \%$ and regular dose of $\mathrm{BB}, \geq 10 \mathrm{mg}$ of carvedilol or $\geq 1.25 \mathrm{mg}$ of bisoprolol (Odds ratio 2.35, 95\% Confidence Interval [CI] 1.12-5.02, P=0.0242; Odds ratio $4.45,95 \% \mathrm{Cl} 2.06-10.27, \mathrm{P}=0.0001$ ).
1 Division of Cardiology, Tokai University School of Medicine, Isehara, Japan.

Contact information:

Yuji Ikari, M.D. Ph.D.

Professor of Medicine, Department of Cardiology.

Address: Tokai University School of Medicine. 143 Shimokasuya, Isehara, 2591193, Japan.

Tel: 81-463-93-1121.

Fax: 81-463-93-6679.

झ"ikari@is.icc.u-tokai.ac.jp 
Conclusions: Immediate BB administration following primary PCI for STEMI provided a dose-dependent LVEF improvement. A LVEF $<50 \%$ and regular dose of $B B$ are predictors of $R R$.

\section{Keywords}

ST-Elevation Myocardial Infarction; Beta-Adrenergic Blockers; Reverse Remodeling; Left Ventricular Ejection Fraction.

\section{Introduction}

Various large clinical trials confirmed that reninangiotensin system inhibitors or beta-adrenergic blockers (BB) have a preventive effect in left ventricular remodeling and improvement in long-term survival. [1-8] Left ventricular reverse remodeling (RR) produced by these optimal medical therapy was recognized as an important surrogate marker toward improvement of clinical outcomes. Current practice guidelines on the management of ST-elevation myocardial infarction (STEMI) recommends immediate BB introduction during hospitalization. $[9,10]$ However, these guidelines are mainly based on data before primary percutaneous coronary intervention $(\mathrm{PCI})$ became the first choice for revascularization.

Recent studies, such as the OACIS trial and posthoc sub-analysis of the J-Cypher registry, proved that BB did not always contribute to the improvement of long-term outcomes in STEMI. $[9,11]$ The beneficial effects seen in those studies were limited in patients with higher risk or low left ventricular ejection fraction (LVEF). These studies suggested potential room for revision regarding BB dose or indication for STEMI in the current era, when prompt revascularization by primary $\mathrm{PCl}$ is a standard therapy.

In this study, serial echocardiographic LVEF data at acute and chronic phase were analyzed to study the relationship between the dosage of $\mathrm{BB}$ and the magnitude of LVEF improvement in STEMI following standard primary $\mathrm{PCl}$.

\section{Methods}

\section{Study design and population.}

To study the relationship between the dosage of BB and the magnitude of LVEF improvement in STEMI following primary $\mathrm{PCl}$, this study surveyed STEMI patients who underwent primary $\mathrm{PCl}$ during January 2006 and March 2015 retrospectively at Tokai University School of Medicine. The BB dose at hospital discharge was assessed for discussion regarding the dosing-improvement relationship.

Inclusion criteria included those patients who were administrated $\mathrm{BB}$ during hospitalization and continued on a fixed dose of BB their echocardiographic LVEF evaluation at the acute phase to the chronic phase. A total of 235 patients were included in the study population and divided into three groups by type of BB administered: no $B B(n=33)$, carvedilol $(n=163)$, or bisoprolol $(n=42)$. To determine the change in LVEF from acute phase to chronic phase, LVEF was evaluated by echocardiography within 3 months from STEMI onset (defined as the acute phase) and at more than 6 months from STE$\mathrm{Ml}$ onset with more than a 5-month interval from acute phase echocardiography (defined as the chronic phase) (Figure 1). 


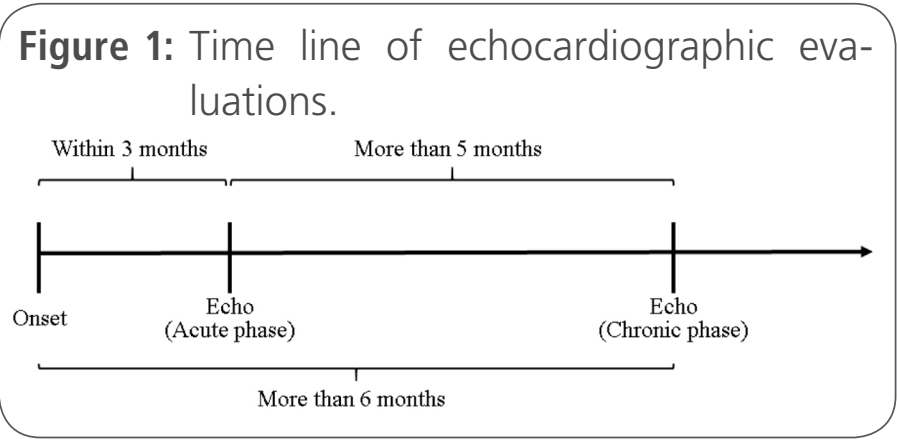

Exclusion criteria were as follows: STEMI patients who did not undergo primary $\mathrm{PCl}$, those whose $\mathrm{BB}$ dose changed during the observation period, those who did not receive renin-angiotensin system inhibitor during observation period, those who had been administrated BB before STEMI onset, those without acute phase echocardiographic evaluation within 3 months from STEMI onset, those without chronic phase echocardiographic evaluation performed more than 5 months from the acute phase echocardiographic evaluation and more than 6 months from STEMI onset, those with new onset of myocardial infarction or any cardiac surgery (including coronary artery bypass grafting) after STE$\mathrm{Ml}$ and during the observation period, and those patients who were treated with a BB other than carvedilol or bisoprolol.

All patients gave written informed consent; this study was designed in accordance with the ethical standards of the General Clinical Research Center of Tokai University School of Medicine. This study obtained all required approvals by the Tokai University institutional review board.

\section{Medications.}

The timing of introduction, dose, or selection of proper medications including BB during hospitalization was determined by an experienced cardiologist team with consideration of patients' general status. All study patients received fixed doses of BB and renin-angiotensin system inhibitor, angiotensin-converting enzyme inhibitor, or angiotensin II receptor blockers during the observation period.

\section{Serial echocardiographic evaluations.}

All echocardiographic studies were performed by an experienced investigator with the patient in the supine position, using the Xario XG with a 1.8-4.2$\mathrm{MHz}$ PST-25AT transducer (Toshiba Medical Systems Corporation; Tochigi, Japan). The recorded echocardiographic data were evaluated and assessed based on the recommendations of the American Society of Echocardiography. [12] To assess the improvement of LVEF and RR effect by BB, serial LVEFs were evaluated by 2-dimensional echocardiography at the acute and chronic phases with a more than 5-month interval between evaluations. Acute phase evaluation was performed under stable hemodynamic status within 3 months after STEMI onset. Chronic phase evaluation was performed at least 6 months from STEMI onset (Figure 1). For 2-dimensional measurements, the LVEF was calculated in apical 4-chamber and apical 2-chamber views at end-diastole and at end-systole by modified Simpson's rule. $[12,13]$ Serial LVEFs at acute and chronic phases were evaluated using the same clearest angle. Papillary muscles were excluded from the cavity in the tracking. End-diastole was defined at the onset of the QRS wave on electrocardiographic (ECG) monitoring, and end-systole was defined as the time of the frame preceding mitral valve opening.

In M-mode recording, the septal wall thickness, posterior wall thickness, and left ventricular internal dimensions were measured over several cardiac cycles in the parasternal short-axis acoustic window to optimize medial-lateral beam orientation. These parameters were measured at the level of the mitral valve leaflet tips at the left ventricular minor axis. The thickness of the ventricular wall and chamber size were measured as the distance between the leading edge echoes.

\section{Definitions}

STEMI was defined as acute when the patient presented within 24 hours of symptom onset and ECG 
findings on arrival showed persistent ST-segment elevation $>1 \mathrm{~mm}$ in two contiguous leads, with new or presumed new left bundle branch block. The final diagnosis was made by emergency coronary angiography, and all patients were underwent primary $\mathrm{PCl}$.

Improvement in LVEF was assessed from the difference calculated by subtracting LVEF at chronic phase from the value determined in the acute phase. RR was defined as LVEF improvement $>10 \%$. $[14,15]$

\section{Statistical analysis}

Numerical factors with normal distribution are shown as mean \pm standard deviation. Numerical factors with skewed distribution are shown as medians (interquartile range). Student's t-test was used to determine statistically significant differences in clinical parameters between two groups with normal distribution. The Wilcoxon rank-sum test was used to determine statistically significant differences in clinical values between two different groups with skewed distribution. Analysis of variance test was performed to compare numerical parameters among the three groups. Fisher's exact test was applied to determine the difference between three categorical variables. The Steel-Dwass test was used to test for between-group differences in numerical factors with skewed distribution. The multiple logistic regression model for examine the parameters to achieve RR included variables with $p<0.10$ in the univariate analysis. The goodness of fit for multivariable analysis was tested by the Hosmer-Lemeshow test. P-values in the tables show the statistical comparison among the three groups. The results of multivariate analysis were summarized by odds ratios (OR) and 95\% confidence intervals $(\mathrm{Cl})$. A value of $\mathrm{P}<0.05$ was considered statistically significant. All statistical calculations were performed using JMP version 11 (SAS Institute, Inc.; Cary, NC, USA).

\section{Results}

To study the relationship between dosage of $\mathrm{BB}$ and the magnitude of LVEF improvement in STEMI following primary $\mathrm{PCl}$, our study examined the serial echocardiographic evaluations at acute and chronic phase. Baseline characteristics are shown in Table 1. Among the total of 235 patients, the mean age

Table 1. Distribution of the domains and facets of QoL. João Pessoa, PB, 2015.

\begin{tabular}{|l|c|c|c|c|c|}
\hline & $\begin{array}{c}\text { Overall } \\
(\mathbf{n = 2 3 5 )}\end{array}$ & $\begin{array}{c}\text { No BB } \\
(\mathbf{n = 3 3 )}\end{array}$ & $\begin{array}{c}\text { Carvedilol } \\
(\mathbf{n = 1 6 0 )}\end{array}$ & $\begin{array}{c}\text { Bisoprolol } \\
(\mathbf{n = 4 2 )}\end{array}$ & P value \\
\hline Age, years & $63.3 \pm 12.1$ & $66.9 \pm 13.7$ & $62.4 \pm 12.1$ & $64.0 \pm 10.8$ & 0.1362 \\
\hline Male & $192(83.8 \%)$ & $23(69.7 \%)$ & $137(85.6 \%)$ & $32(76.2 \%)$ & 0.0584 \\
\hline Height, cm & $162.5 \pm 8.3$ & $160.0 \pm 8.6$ & $163.5 \pm 7.9$ & $161.0 \pm 9.1$ & 0.0292 \\
\hline Weight, kg & $64.1 \pm 13.0$ & $58.5 \pm 12.6$ & $65.7 \pm 12.8$ & $62.3 \pm 12.8$ & 0.0084 \\
\hline Current smoking & $90(38.3 \%)$ & $8(24.2 \%)$ & $70(43.8 \%)$ & $12(28.6 \%)$ & 0.0834 \\
\hline Diabetes mellitus & $79(33.6 \%)$ & $14(42.4 \%)$ & $55(34.4 \%)$ & $10(23.8 \%)$ & 0.2233 \\
\hline Insulin & $7(3.0 \%)$ & $2(6.1 \%)$ & $5(3.1 \%)$ & 0 & 0.3033 \\
\hline Dyslipidemia & $173(73.6 \%)$ & $19(57.6 \%)$ & $126(78.8 \%)$ & $28(66.7 \%)$ & 0.0270 \\
\hline Hypertension & $173(73.6 \%)$ & $25(75.8 \%)$ & $121(75.6 \%)$ & $27(64.3 \%)$ & 0.3178 \\
\hline Family history & $31(13.2 \%)$ & $4(12.1 \%)$ & $22(13.8 \%)$ & $5(11.9 \%)$ & 0.9336 \\
\hline Prior PCI & $22(9.4 \%)$ & $3(9.1 \%)$ & $13(8.1 \%)$ & $6(14.3 \%)$ & 0.4744 \\
\hline Prior CABG & $1(0.4 \%)$ & 0 & $1(0.6 \%)$ & 0 & 0.7903 \\
\hline
\end{tabular}




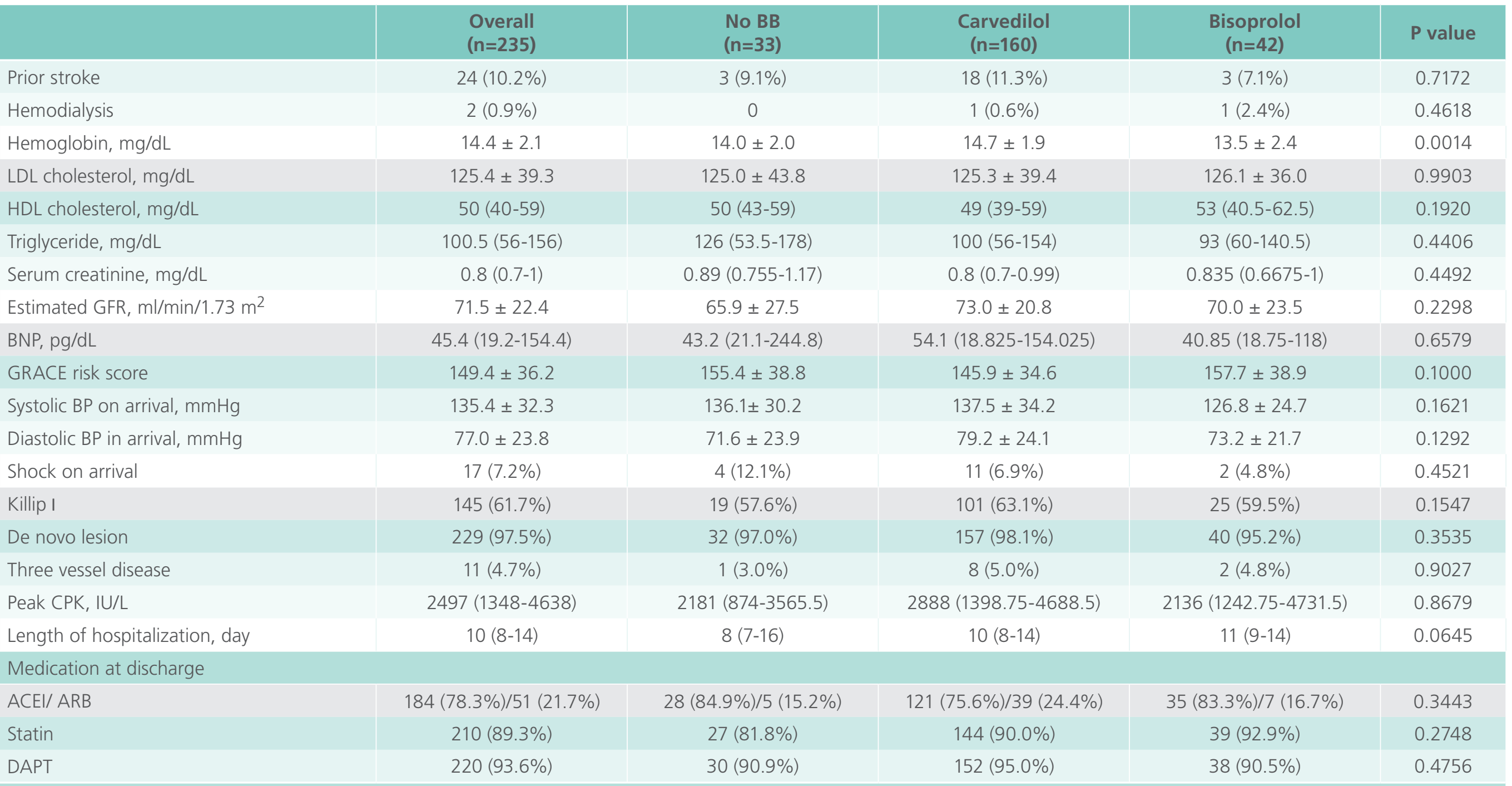

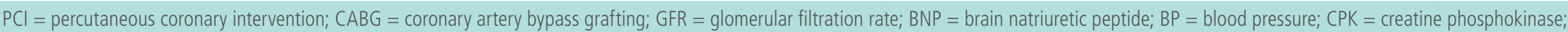
$\mathrm{ACEI}=$ angiotensin converting enzyme inhibitor; $\mathrm{ARB}=$ angiotensin II receptor blocker; DAPT = dual antiplatelet therapy; $B \mathrm{~B}=$ beta adrenergic receptor blocker 
was $63.3 \pm 12.1$ years, and $83.8 \%$ of patients were male. Blood pressure, shock vitals, decompensated heat failure, GRACE risk score on onset and peak creatine phosphokinase after primary $\mathrm{PCl}$ were not significantly different across the three groups. Medications at hospital discharge (including renin-angiotensin system inhibitor, statins, and antiplatelet therapy) were not significantly different across the three groups.

\section{Serial echocardiographic evaluations}

Table 2 shows the result of serial echocardiographic evaluations. The median interval of serial echocardiographic evaluations from acute to chronic phase was 526 days (range: 300 to 1041 days), and from STEMI onset to chronic phase echocardiographic evaluation was 537 days (range: 303 to 1042 days). The mean LVEFs at the acute and chronic

Table 2. Serial echocardiographic evaluations.

\begin{tabular}{|c|c|c|c|c|c|}
\hline & $\begin{array}{l}\text { Overall } \\
(n=235)\end{array}$ & $\begin{array}{l}\text { No BB } \\
(n=33)\end{array}$ & $\begin{array}{l}\text { Carvedilol } \\
(n=160)\end{array}$ & $\begin{array}{l}\text { Bisoprolol } \\
(n=42)\end{array}$ & $P$ value \\
\hline \multicolumn{6}{|l|}{ Acute phase } \\
\hline Days from onset, day & $2(1-11)$ & $1(1-9.5)$ & $2(1-13)$ & $2(1-5.25)$ & 0.3901 \\
\hline LVEF, \% & $53.9 \pm 9.9$ & $58.5 \pm 12.5$ & $53.0 \pm 9.4$ & $53.6 \pm 8.9$ & 0.0134 \\
\hline $\mathrm{LA}, \mathrm{mm}$ & $34.1 \pm 7.1$ & $34.5 \pm 9.3$ & $33.9 \pm 6.6$ & $34.5 \pm 7.5$ & 0.8308 \\
\hline LVDd, mm & $49.7 \pm 6.8$ & $49.3 \pm 8.5$ & $49.8 \pm 6.6$ & $49.3 \pm 5.9$ & 0.8866 \\
\hline LVDs, mm & $32.2 \pm 6.9$ & $32.3 \pm 8.0$ & $32.7 \pm 6.9$ & $31.6 \pm 6.0$ & 0.5880 \\
\hline IVS, mm & $11.0 \pm 2.3$ & $10.7 \pm 2.2$ & $11.2 \pm 2.3$ & $10.5 \pm 2.2$ & 0.2505 \\
\hline PW, mm & $10.4 \pm 1.8$ & $10.4 \pm 2.0$ & $10.5 \pm 1.7$ & $10.4 \pm 1.7$ & 0.9247 \\
\hline $\mathrm{EDV}, \mathrm{mL}$ & $122.5 \pm 34.6$ & $115.8 \pm 42.2$ & $123.7 \pm 33.8$ & $123.3 \pm 31.4$ & 0.5211 \\
\hline $\mathrm{ESV}, \mathrm{mL}$ & $45.0 \pm 23.0$ & $43.2 \pm 25.7$ & $46.2 \pm 23.9$ & $42.9 \pm 18.1$ & 0.6555 \\
\hline$E / A$ & $0.9 \pm 0.5$ & $0.9 \pm 0.5$ & $0.9 \pm 0.5$ & $0.9 \pm 0.4$ & 0.8440 \\
\hline DcT, msec & $0.21 \pm 0.10$ & $0.21 \pm 0.05$ & $0.20 \pm 0.08$ & $0.23 \pm 0.19$ & 0.3123 \\
\hline \multicolumn{6}{|l|}{ Late phase } \\
\hline Days from onset, day & 537 (303-1042) & $414(212-816)$ & $560(338.75-1312.5)$ & $456(282.25-838.5)$ & 0.0031 \\
\hline $\begin{array}{l}\text { Interval from } 1^{\text {st }} \\
\text { echocardiography }\end{array}$ & 526 (300-1041) & $413(210.5-813)$ & $541(334-1282.75)$ & $453(277.5-814)$ & 0.0034 \\
\hline LVEF, \% & $56.4 \pm 10.6$ & $54.1 \pm 12.7$ & $56.6 \pm 10.0$ & $57.4 \pm 11.3$ & 0.3783 \\
\hline $\mathrm{LA}, \mathrm{mm}$ & $36.4 \pm 7.6$ & $37.6 \pm 9.7$ & $35.8 \pm 6.4$ & $37.7 \pm 9.7$ & 0.2120 \\
\hline LVDd, mm & $51.2 \pm 7.0$ & $50.7 \pm 7.2$ & $51.3 \pm 7.2$ & $51.0 \pm 6.3$ & 0.9076 \\
\hline LVDs, mm & $33.2 \pm 7.8$ & $34.2 \pm 8.7$ & $33.0 \pm 7.6$ & $33.0 \pm 8.0$ & 0.7588 \\
\hline IVS, mm & $10.3 \pm 2.1$ & $10.3 \pm 1.7$ & $10.3 \pm 2.1$ & $10.0 \pm 2.3$ & 0.5695 \\
\hline PW, mm & $9.8 \pm 1.5$ & $9.8 \pm 1.5$ & $9.8 \pm 1.5$ & $9.7 \pm 1.3$ & 0.8965 \\
\hline $\mathrm{EDV}, \mathrm{mL}$ & $123.5 \pm 39.0$ & $128.1 \pm 49.7$ & $122.9 \pm 38.0$ & $122.0 \pm 33.9$ & 0.7764 \\
\hline $\mathrm{ESV}, \mathrm{mL}$ & $46.7 \pm 25.4$ & $46.8 \pm 24.2$ & $46.2 \pm 25.6$ & $48.2 \pm 26.4$ & 0.9130 \\
\hline$E / A$ & $0.9 \pm 0.5$ & $0.8 \pm 0.3$ & $0.8 \pm 0.3$ & $1.1 \pm 1.0$ & 0.0299 \\
\hline DcT, msec & $0.23 \pm 0.06$ & $0.21 \pm 0.04$ & $0.23 \pm 0.07$ & $0.21 \pm 0.04$ & 0.1017 \\
\hline
\end{tabular}

LVEF = left ventricular ejection fraction; LA = left atrium; LVDd = left ventricular diastolic diameter; LVDs = left ventricular systolic diameter; IVS = interventriclr septum; PW = posterior wall; EDV = end-diastolic volume; ESV = end-systolic volume; $E / A=$ early diastolic filling velocity/ atrial filling velocity; DCT = decelaration time; $B B=$ beta adrenergic receptor blocker 
phases in the overall population were $53.9 \pm 9.9 \%$ and $56.4 \pm 10.6 \%$, respectively. In the evaluation during the acute phase, the no BB group had a significantly lower LVEF than the BB group (carvedilol and bisoprolol groups combined) $(P=0.0134)$. The changes in end-systolic volume (ESV), end-diastolic volume (EDV), and LVEF are shown in Figure 2. The ESV showed no significant differences regardless of $B B$ therapy or no BB therapy $(P=0.3422)$, and EDV in no $B B$ group showed a significant increase at the chronic phase evaluation than seen in the $B B$ therapy group $(P=0.0171)$. The LVEF decreased at chronic phase evaluation point in the no BB group; on the other hand, the BB therapy groups showed LVEF improvement (-4\% [range: -8 to $-1 \%$ ] vs. $+2 \%$ [range: 0 to $7.3 \%$ ], $\mathrm{P}<0.0001)$. In comparison across the three groups, no BB vs. carvedilol vs. bisoprolol,

Figure 2: Comparisons of ESV, EDV, and LVEF transitions between no $\mathrm{BB}$ and $\mathrm{BB}$ treatment.
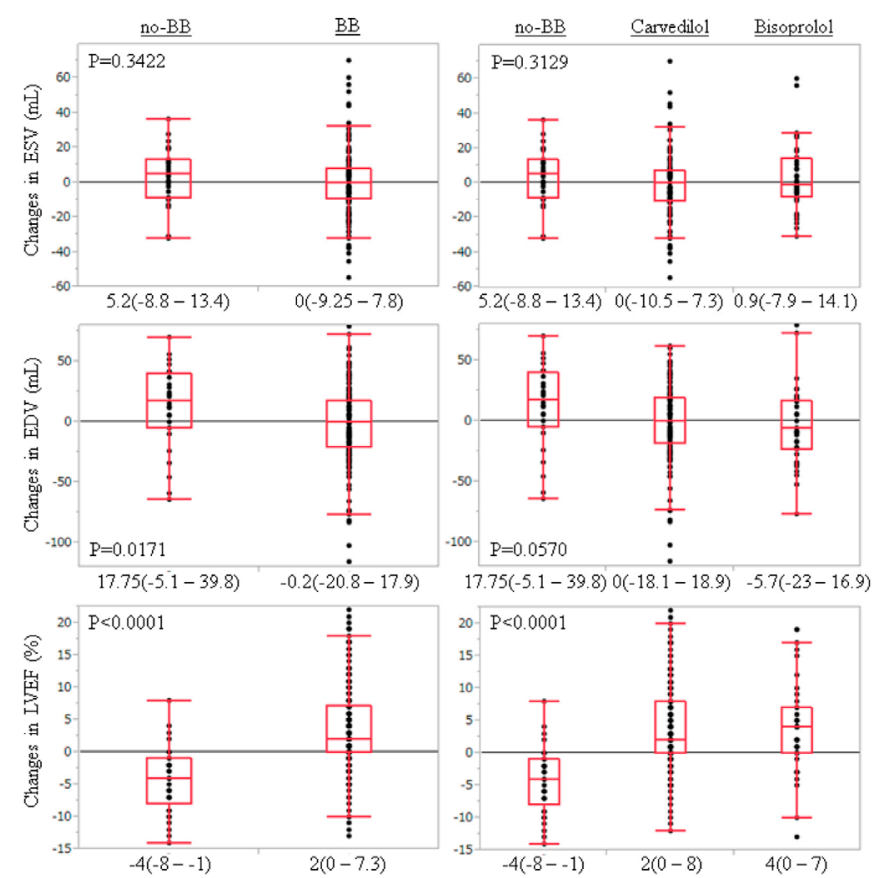

Changes in ESV, EDV, and LVEF from acute to chronic phase are demonstrated by BB therapy. The EDV with no BB therapy was significantly greater than seen with $B B$ therapy; however, there was no significant difference in ESV. The LVEF decreased in the no BB group, but improvement was shown in the BB group, carvedilol, and bisoprolol group. both the carvedilol and bisoprolol groups showed LVEF improvement (-4\% [range: -8 to $-1 \%$ ] vs. $+2 \%$ [range: 0 to $8 \%$ ] vs. $+4 \%$ [range: 0 to $7 \%$ ], respectively; $\mathrm{P}<0.0001)$.

\section{Dose-dependence of BB efficacy for LVEF improvement}

To study the relationship between dosage of $\mathrm{BB}$ and the magnitude of LVEF improvement, LVEF improvement was analyzed by dividing into subgroup according to BB dose (Figure 3). The no BB and carvedilol groups were divided into three subgroups: minimum dose: $<5 \mathrm{mg}(\mathrm{n}=65)$, medium dose: $\geq 5 \mathrm{mg}$ and $<10$ $m g(n=64)$, and regular dose: $\geq 10 \mathrm{mg}(n=64)$. The minimum dose of carvedilol did not have sufficient effect to improve LVEF, however the magnitude of LVEF improvement with carvedilol increased dose-

Figure 3: Dose-dependence of BB to LVEF improvement.

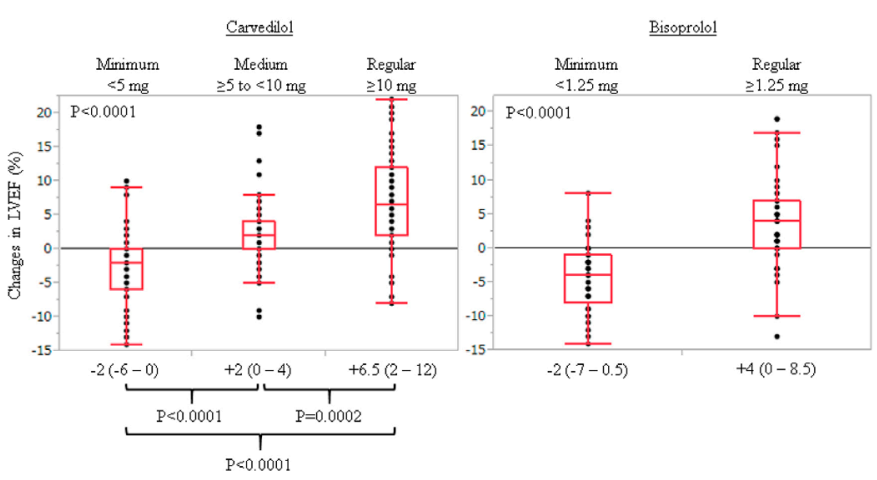

The changes in LVEF were demonstrated in the carvedilol (left panel) and bisoprolol (right panel) groups, which was classified according to BB dosage at hospital discharge. The carvedilol group was divided three subgroups: minimum dose $(<5 \mathrm{mg})$, medium dose ( $\geq 5 \mathrm{mg}$ and $<10 \mathrm{mg}$ ), and regular dose ( $\geq 10 \mathrm{mg}$ ). The LVEF decreased $-2 \%$ from that of baseline with the minimum dose. In contrast, the medium dose demonstrated $+2 \%$ improvement with a significant difference compared to the minimum dose. Moreover, the regular dose demonstrated a significantly better $+6.5 \%$ improvement than seen with the medium dose. The RR achievement rate was $1.5 \%(1 / 65), 14.1 \%$ $(9 / 64)$, and $32.8 \%(21 / 64)$, respectively $(P<0.0001)$. The bisoprolol group was divided into two subgroups: minimum dose $(<1.25 \mathrm{mg})$ and regular dose $(\geq 1.25 \mathrm{mg})$. The minimum dose didn't produce LVEF improvement, but the regular dose did $(-2 \%$ vs. $+4 \%, P<0.0001)$. In these patients, the RR achievement rate was $0 \%(0 / 42)$ and $21.2 \%(7 / 44)$, respectively $(P=0.0022)$. 
dependently $(-2 \%$ with minimum dose [range: -6 to $0 \%$ ] vs. $+2 \%$ with medium dose [range: 0 to $4 \%$ ] vs. $+6.5 \%$ with regular dose [range: 2 to $12 \%$, $\mathrm{P}<0.0001$; left panel, Figure 3). The RR achievement rate among these subgroups also showed dose-dependent increases of 1.5\% (1/65), 14.1\% (9/64), and $32.8 \%(21 / 64)$, respectively $(\mathrm{P}<0.0001)$.

The no BB and bisoprolol groups were divided into two subgroups: minimum dose: $<1.25 \mathrm{mg}(\mathrm{n}=42)$ and regular dose: $\geq 1.25 \mathrm{mg}(n=33)$. As seen with carvedilol, minimum dose bisoprolol didn't demonstrated LVEF improvement, and the regular dose did lead to LVEF improvement (-2\% [range: -7 to $0.5 \%$ ] vs. $+4 \%$ [range: 0 to $8.5 \%$ ], $\mathrm{P}<0.0001$; right panel, Figure 3). The RR achievement rate was 0\% (0/42) and $21.2 \%$ (7/44), respectively $(P=0.0022)$.

\section{Multivariate analysis for predictors of left ventricular reverse remodeling}

RR was shown in $16.2 \%$ of the overall population. BB therapy with carvedilol and bisoprolol showed a significantly higher $\mathrm{RR}$ achievement rate than did the no BB group (no BB group 0\%, carvedilol group $19.4 \%$, bisoprolol group 16.7\%, $\mathrm{P}=0.0225$ ).

To identify the clinical predictors of RR, the following variables were examined by multivariate logistic analysis: age, male gender, diabetes mellitus, estimated GFR, LVEF <50\% at acute phase, angiotensin-converting enzyme inhibitor use (compared to angiotensin II receptor blockers), statin use, and regular dose of $\mathrm{BB}$ ( $\geq 10 \mathrm{mg}$ of carvedilol or $\geq 1.25$ mg of bisoprolol) (Table 3). Both LVEF $<50 \%$ at acute phase and regular dose of $\mathrm{BB}$ were found to be independent predictors of RR (LVEF $<50 \%$ at acute phase: Odds ratio $2.35,95 \% \mathrm{Cl} 1.12-5.02$, $\mathrm{P}=0.0242$; regular dose of $\mathrm{BB}$ : Odds ratio $4.45,95 \%$ $\mathrm{Cl} 2.06-10.27, \mathrm{P}=0.0001)$.

To confirm the above results of multivariate analysis, the three groups were further divided into subgroups according to LVEF $<50 \%$ and regular dose of BB: baseline LVEF $<50 \%$ and receiving $\geq 10$ mg of carvedilol $(n=34)$ or not $(n=159)$, or $\geq 1.25$ mg of bisoprolol $(n=15)$ or not $(n=60)$ (Figure 4$)$. In
Table 3. Multivariable analysis for predictors of left ventricular reverse remodeling.

\begin{tabular}{|c|c|c|c|}
\hline \multirow[b]{2}{*}{ Variables } & \multirow{2}{*}{$\begin{array}{c}\text { Univariate } \\
\text { P value } \\
(95 \% \mathrm{Cl})\end{array}$} & \multicolumn{2}{|c|}{ Multivariate } \\
\hline & & $\begin{array}{l}\text { Odds ratio } \\
(95 \% \mathrm{Cl})\end{array}$ & $\begin{array}{c}\text { P } \\
\text { value }\end{array}$ \\
\hline Age & $\begin{array}{c}0.5213 \\
(0.98-1.03)\end{array}$ & & \\
\hline Male & $\begin{array}{c}0.1526 \\
(0.13-1.28)\end{array}$ & & \\
\hline Diabetes mellitus & $\begin{array}{c}0.1193 \\
(0.28-1.16)\end{array}$ & & \\
\hline Estimated GFR & $\begin{array}{c}0.2975 \\
(0.99-1.02)\end{array}$ & & \\
\hline $\begin{array}{l}\text { Baseline LVEF } \\
<50 \%\end{array}$ & $\begin{array}{c}0.0020 \\
(1.50-6.33)\end{array}$ & $\begin{array}{c}2.35 \\
(1.12-5.02)\end{array}$ & 0.0242 \\
\hline $\begin{array}{l}\text { Favor ACEl over } \\
\text { ARB }\end{array}$ & $\begin{array}{c}0.2498 \\
(0.71-3.43)\end{array}$ & & \\
\hline Statin & $\begin{array}{c}0.1121 \\
(0.82-5.63)\end{array}$ & & \\
\hline $\begin{array}{l}\text { Regular dose of } \\
\mathrm{BB} \neq\end{array}$ & $\begin{array}{c}<0.0001 \\
(2.45-11.83)\end{array}$ & $\begin{array}{c}4.45 \\
(2.06-10.27)\end{array}$ & 0.0001 \\
\hline \multicolumn{4}{|c|}{ 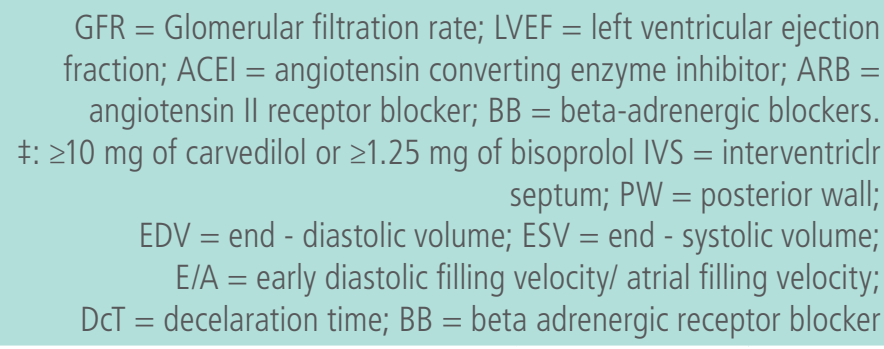 } \\
\hline
\end{tabular}

Figure 4: Impact of regular dose of $B B$ in LVEF
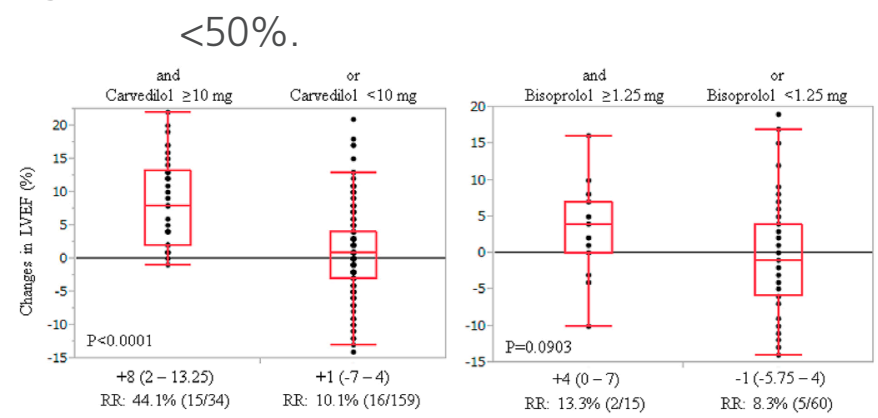

The impact of the regular dose of $B B$, which is $\geq 10 \mathrm{mg}$ of carvedilol or $\geq 1.25$ $\mathrm{mg}$ of bisoprolol, on the magnitude of LVEF improvement in patients where the LVEF $<50 \%$ was assessed.

In the carvedilol group, patients with an LVEF $<50 \%$ treated with regular dose $(n=34)$ had $+8 \%$ (range: 2 to $13.25 \%)$, and another $(n=159)$ had $+1 \%$ (range: -7 to $4 \%$ ) change in LVEF $(P<0.0001)$. The RR achievement rates for these patients were $44.1 \%$ and $10.1 \%(P=0.0006)$, respectively.

In the bisoprolol group, the change in LVEF was $+4 \%$ (range: 0 to $7 \%$ ) and $-1 \%$ (range: -5.75 to $4 \%$ ), respectively $(P=0.0903)$. The RR achievement rates were $13.3 \%(2 / 15)$ and $8.3 \%(5 / 60)$, respectively $(P=0.6217)$. 
the carvedilol group, the change in LVEF in the "EF $<50 \%$ and $>10$ mg group" compared with the "EF $\geq 50 \%$ or $<10 \mathrm{mg}$ group" was $+8 \%$ (range: 2 to $13.25 \%$ ), and another was $+1 \%$ (range: -7 to $4 \%$ ) $(\mathrm{P}<0.0001)$. The RR achievement rates were $44.1 \%$ (15/34) and 10.1\% (16/159), respectively ( $P=0.0006)$. In the bisoprolol group, the same tendency was demonstrated, although there was no significant difference: $+4 \%$ (range: 0 to $7 \%$ ) vs. $-1 \%$ (range: -5.75 to $4 \%), P=0.0903$. The $R R$ achievement rate was $13.3 \%(2 / 15$; the $\mathrm{EF}<50 \%$ and $>1.25 \mathrm{mg}$ group) and $8.3 \%$ (5/60; the $\mathrm{EF}>50 \%$ or $<1.25 \mathrm{mg}$ group), respectively $(P=0.6217)$.

\section{Discussion}

This study revealed the relationship between BB dose and the magnitude of LVEF improvement in STEMI following primary $\mathrm{PCl}$ using serial echocardiography assessment. Early BB introduction was related to improvement of LVEF and dose-dependent RR achievement. Baseline LVEF $<50 \%$ and regular dose of BB administration were suggested as independent predictors of RR achievement.

It is well-established that BB has efficacy in improving LVEF and long-term outcomes in chronic heart failure. [16-22] On the other hand, the impact of BB therapy on STEMI immediately after successful primary $\mathrm{PCl}$ may be discussed separately from that of chronic heart failure. In the 2013 American College of Cardiology Foundation/American Heart Association guidelines for treatment of patients with STEMI, BB therapy is recommended for all STEMI patients who do not have signs of heart failure, low output state, increased risk for cardiogenic shock, or other contraindications defined as Class I. [10] In the 2012 European Society of Cardiology guidelines for treatment of patients with STEMI, BB therapy is recommended for STEMI patients with heart failure or left ventricular dysfunction defined as Class IA, and for all STEMI patients without contraindications defined as Class Ila. [23] However, most of these recommendations were based on data obtained before the primary PCl era. [24-32] Recently, some trials have raised an important question regarding BB therapy for STEMI patients. The OACIS trial demonstrated that BB was not always beneficial for all STEMI patients, since low-risk patients defined according to the GRACE risk score did not have clinical benefits. [11] Post-hoc sub-analysis of the J-Cypher registry showed BB therapy produced no significant difference in 3-year mortality or in incidence of major adverse cardiac events in STEMI patients with primary $\mathrm{PCl}$, and only patients with LVEF $\leq 40 \%$ showed improvement in these outcomes. [9] Moreover, sub-analysis of the VALIANT trial demonstrated the additional benefit of $B B$ on renin-angiotensin system inhibitors was unclear in acute myocardial infarction. [33] In the REACH registry, which analyzed over 44,000 patients with prior myocardial infarction, BB therapy did not show superiority in primary outcome of cardiovascular death, nonfatal $\mathrm{MI}$, or nonfatal stroke, even after propensity score-matched adjustment. [34] A metaanalysis published in 2015 showed that depressed LVEF, non-STEMI, and undertreated therapies were suggested as a beneficial subgroup with BB in acute myocardial infarction. [35]

The present study demonstrated that ESV did not change between acute and chronic phases, but EDV decreased significantly. This finding suggests that the effect of BB was prevention of left ventricular dilation, rather than improvement of systolic function. The CAPRICORN Echo Substudy demonstrated $+5 \%$ improvement of LVEF with carvedilol at 6 months after acute myocardial infarction. [36] \Although CAPRICORN did not analyze the dosage of carvedilol, the efficacy is considered as equivalent to our results. As with the above suggestions from the OACIS trial and J-Cypher registry, decreased LVEF patients were evaluated as a subgroup sensitive for BB efficacy. [9, 11]

The necessary BB dosage to improve LVEF or achieve RR has not been discussed enough, 
because the major focus in prior studies was whether administration of BBs was better than no administration. Since it is quite unlikely that a minimum dose of BB could improve enough LVEF or RR significantly, the next problem in clinical implications is how much we should increase the dosage when the patients are discharged from the hospital. [37-39] Our study suggests that a minimum dose of BB was not sufficient to achieve RR. Thus, it may be necessary to increase up to regular dose at hospital discharge in STEMI patients following primary $\mathrm{PCl}$. [40-46] Prospective investigation is required to confirm our suggestion, BB administration during 6 months improve LVEF dose-dependently among $<5 \mathrm{mg}$, $\geq 5$ to $<10 \mathrm{mg}$, and $\geq 10 \mathrm{mg}$ of carvedilol, and between $<1.25 \mathrm{mg}$ and $\geq 1.25 \mathrm{mg}$ of bisoprolol.

There are several limitations in our study. First, this was a retrospective study. Second, the study may have been underpowered to draw a conclusion on efficacy of BB therapy on LVEF improvement. Third, the duration of BB therapy did not include the present discussion, since the duration of BB therapy and interval of echocardiographic evaluation differed between individuals studied. Fourth, other medications, excluding BB and reninangiotensin system inhibitor, were not included the present discussion. Fifth, patient compliance with medication is less clear. Present study did not assess the impact of BB initiation timing on LVEF improvement although Bugiardini et al reported earlier administration of oral BB therapy with a greater probability of improving LV function and in-hospital survival rate. [47]

In conclusion, immediate BB administration after STEMI onset following primary $\mathrm{PCl}$ provides a dosedependent LVEF improvement. For patients with decreased LVEF $<50 \%$, administration of the regular dose of BB might be reasonable to achieve RR.

\section{Abbreviations}

BB: beta-adrenergic blockers

RR: Left ventricular reverse remodeling

STEMI: ST-elevation myocardial infarction

$\mathrm{PCl}$ : percutaneous coronary intervention

LVEF: left ventricular ejection fraction

ECG: electrocardiographic

OR: odds ratios

$\mathrm{Cl}$ : confidence intervals

ESV: end-systolic volume

EDV: end-diastolic volume

\section{Funding}

This research did not receive any specific grant from funding agencies in the public, commercial, or notfor-profit sectors.

\section{Acknowledgements}

No other persons have made substantial contributions to this manuscript.

\section{Conflict of interest}

The authors declare that they have no conflict of interest.

\section{References}

1. Pfeffer MA, Braunwald E, Moye LA, Basta L, Brown EJ, Jr., Cuddy $T E$, et al. Effect of captopril on mortality and morbidity in patients with left ventricular dysfunction after myocardial infarction. Results of the survival and ventricular enlargement trial. The SAVE Investigators. N Engl J Med 1992; 327:669-677.

2. Swedberg K, Held P, Kjekshus J, Rasmussen K, Ryden L, Wedel $\mathrm{H}$. Effects of the early administration of enalapril on mortality in patients with acute myocardial infarction. Results of the Cooperative New Scandinavian Enalapril Survival Study II (CONSENSUS II). N Engl J Med 1992; 327:678-684.

3. Rouleau JL, de Champlain J, Klein M, Bichet D, Moye L, Packer $M$, et al. Activation of neurohumoral systems in postinfarction left ventricular dysfunction. J Am Coll Cardiol 1993; 22:390398.

4. Yoshiyama M, Takeuchi K, Omura T, Izutani S, Nakamura $Y$, Akioka $K$, et al. Effect of diltiazem on cardiac remodeling in rats assessed by Doppler echocardiography and mRNA expression. Cardiovasc Drugs Ther 1999; 13:249-258. 
5. Silvestre JS, Heymes C, Oubenaissa A, Robert V, AupetitFaisant B, Carayon A, et al. Activation of cardiac aldosterone production in rat myocardial infarction: effect of angiotensin II receptor blockade and role in cardiac fibrosis. Circulation 1999; 99:2694-2701.

6. Mizuno $Y$, Yoshimura $M$, Yasue $H$, Sakamoto $T$, Ogawa $H$, Kugiyama $\mathrm{K}$, et al. Aldosterone production is activated in failing ventricle in humans. Circulation 2001; 103:72-77.

7. Yusuf S, Teo K, Anderson C, Pogue J, Dyal L, Copland I, et al. Effects of the angiotensin-receptor blocker telmisartan on cardiovascular events in high-risk patients intolerant to angiotensin-converting enzyme inhibitors: a randomised controlled trial. Lancet 2008; 372:1174-1183.

8. Miyazaki M, Takai S. Local angiotensin I-generating system in vascular tissues: the roles of chymase. Hypertens Res 2001; 24:189-193.

9. Ozasa N, Kimura T, Morimoto T, Hou H, Tamura T, Shizuta S, et al. Lack of effect of oral beta-blocker therapy at discharge on long-term clinical outcomes of ST-segment elevation acute myocardial infarction after primary percutaneous coronary intervention. Am J Cardiol 2010; 106:1225-1233.

10. O'Gara PT, Kushner FG, Ascheim DD, Casey DE, Jr., Chung MK, de Lemos JA, et al. 2013 ACCF/AHA guideline for the management of ST-elevation myocardial infarction: a report of the American College of Cardiology Foundation/American Heart Association Task Force on Practice Guidelines. Circulation 2013; 127:e362-425.

11. Nakatani $D$, Sakata $Y$, Suna $S$, Usami M, Matsumoto $S$, Shimizu $M$, et al. Impact of beta blockade therapy on long-term mortality after ST-segment elevation acute myocardial infarction in the percutaneous coronary intervention era. Am J Cardiol 2013; 111:457-464.

12. Lang RM, Bierig M, Devereux RB, Flachskampf FA, Foster E, Pellikka PA, et al. Recommendations for chamber quantification: a report from the American Society of Echocardiography's Guidelines and Standards Committee and the Chamber Quantification Writing Group, developed in conjunction with the European Association of Echocardiography, a branch of the European Society of Cardiology. J Am Soc Echocardiogr 2005; 18:1440-1463.

13. Schiller NB, Acquatella $H$, Ports TA, Drew D, Goerke J, Ringertz $\mathrm{H}$, et al. Left ventricular volume from paired biplane twodimensional echocardiography. Circulation 1979; 60:547-555.

14. Murphy NF, O'Loughlin C, Ledwidge M, McCaffrey $D$, McDonald K. Improvement but no cure of left ventricular systolic dysfunction in treated heart failure patients. Eur J Heart Fail 2007; 9:1196-1204.

15. Merlo M, Pyxaras SA, Pinamonti B, Barbati G, Di Lenarda A, Sinagra G. Prevalence and prognostic significance of left ventricular reverse remodeling in dilated cardiomyopathy receiving tailored medical treatment. J Am Coll Cardiol 2011; 57:1468-1476.
16. Olsen SL, Gilbert EM, Renlund DG, Taylor DO, Yanowitz FD, Bristow MR. Carvedilol improves left ventricular function and symptoms in chronic heart failure: a double-blind randomized study. J Am Coll Cardiol 1995; 25:1225-1231.

17. Bristow MR, Gilbert EM, Abraham WT, Adams KF, Fowler $M B$, Hershberger RE, et al. Carvedilol produces dose-related improvements in left ventricular function and survival in subjects with chronic heart failure. MOCHA Investigators. Circulation 1996; 94:2807-2816.

18. Groenning BA, Nilsson JC, Sondergaard L, Fritz-Hansen T, Larsson HB, Hildebrandt PR. Antiremodeling effects on the left ventricle during beta-blockade with metoprolol in the treatment of chronic heart failure. J Am Coll Cardiol 2000; 36:2072-2080.

19. Remme WJ, Committee CS, Investigators. The Carvedilol and ACE-Inhibitor Remodelling Mild Heart Failure EvaluatioN trial (CARMEN)--rationale and design. Cardiovasc Drugs Ther 2001; 15:69-77

20. Hori M, Sasayama S, Kitabatake A, Toyo-oka T, Handa S, Yokoyama M, et al. Low-dose carvedilol improves left ventricular function and reduces cardiovascular hospitalization in Japanese patients with chronic heart failure: the Multicenter Carvedilol Heart Failure Dose Assessment (MUCHA) trial. Am Heart J 2004; 147:324-330.

21. Colucci WS, Kolias TJ, Adams KF, Armstrong WF, Ghali JK, Gottlieb SS, et al. Metoprolol reverses left ventricular remodeling in patients with asymptomatic systolic dysfunction: the REversal of VEntricular Remodeling with Toprol-XL (REVERT) trial. Circulation 2007; 116:49-56.

22. Okamoto $H$, Hori $M$, Matsuzaki $M$, Tsutsui $H$, Yamazaki $T$, Nagai $R$, et al. Minimal dose for effective clinical outcome and predictive factors for responsiveness to carvedilol: Japanese chronic heart failure (J-CHF) study. Int J Cardiol 2013; 164:238244.

23. Steg PG, James SK, Atar D, Badano LP, Blomstrom-Lundqvist $C$, Borger MA, et al. ESC Guidelines for the management of acute myocardial infarction in patients presenting with ST-segment elevation. Eur Heart J 2012; 33:2569-2619.

24. Timolol-induced reduction in mortality and reinfarction in patients surviving acute myocardial infarction. N Engl J Med 1981; 304:801-807.

25. A randomized trial of propranolol in patients with acute myocardial infarction. I. Mortality results. JAMA 1982; 247:17071714.

26. A randomized trial of propranolol in patients with acute myocardial infarction. II. Morbidity results. JAMA 1983; 250:2814-2819.

27. Yusuf S, Peto R, Lewis J, Collins R, Sleight P. Beta blockade during and after myocardial infarction: an overview of the randomized trials. Prog Cardiovasc Dis 1985; 27:335-371.

28. Gottlieb SS, McCarter RJ, Vogel RA. Effect of beta-blockade on mortality among high-risk and low-risk patients after myocardial infarction. N Engl J Med 1998; 339:489-497. 
29. Freemantle N, Cleland J, Young P, Mason J, Harrison J. beta Blockade after myocardial infarction: systematic review and meta regression analysis. BMJ 1999; 318:1730-1737.

30. Basu S, Senior R, Raval U, van der Does R, Bruckner T, Lahiri A. Beneficial effects of intravenous and oral carvedilol treatment in acute myocardial infarction. A placebo-controlled, randomized trial. Circulation 1997; 96:183-191.

31. Senior R, Basu S, Kinsey C, Schaeffer S, Lahiri A. Carvedilol prevents remodeling in patients with left ventricular dysfunction after acute myocardial infarction. Am Heart J 1999; 137:646652.

32. Kernis SJ, Harjai KJ, Stone GW, Grines LL, Boura JA, O'Neill WW, et al. Does beta-blocker therapy improve clinical outcomes of acute myocardial infarction after successful primary angioplasty? J Am Coll Cardiol 2004; 43:1773-1779.

33. Califf RM, Lokhnygina Y, Velazquez EJ, McMurray JJ, Leimberger $J D$, Lewis EF, et al. Usefulness of beta blockers in high-risk patients after myocardial infarction in conjunction with captopril and/or valsartan (from the VALsartan In Acute Myocardial Infarction [VALIANT] trial). Am J Cardiol 2009; 104:151-157.

34. Bangalore S, Steg G, Deedwania P, Crowley K, Eagle KA, Goto $S$, et al. beta-Blocker use and clinical outcomes in stable outpatients with and without coronary artery disease. JAMA 2012; 308:1340-1349

35. Huang BT, Huang FY, Zuo ZL, Liao YB, Heng Y, Wang PJ, et al. Meta-Analysis of Relation Between Oral beta-Blocker Therapy and Outcomes in Patients With Acute Myocardial Infarction Who Underwent Percutaneous Coronary Intervention. Am J Cardiol 2015; 115:1529-1538.

36. Dargie HJ. Effect of carvedilol on outcome after myocardial infarction in patients with left-ventricular dysfunction: the CAPRICORN randomised trial. Lancet 2001; 357:1385-1390.

37. Goldberger JJ, Bonow RO, Cuffe M, Dyer A, Rosenberg $Y$, O'Rourke $R$, et al. beta-Blocker use following myocardial infarction: low prevalence of evidence-based dosing. Am Heart J 2010; 160:435-442 e431.

38. Grall S, Biere L, Le Nezet M, Bouvier JM, Lucas-Chauvelon P, Richard C, et al. Relationship between beta-blocker and angiotensin-converting enzyme inhibitor dose and clinical outcome following acute myocardial infarction. Circ J 2015; 79:632-640

39. Zhang H, Masoudi FA, Li J, Wang Q, Li X, Spertus JA, et al. National assessment of early beta-blocker therapy in patients with acute myocardial infarction in China, 2001-2011: The China Patient-centered Evaluative Assessment of Cardiac Events (PEACE)-Retrospective AMI Study. Am Heart J 2015; 170:506515 e501.

40. Jonsson G, Abdelnoor M, Muller C, Kjeldsen SE, Os I, Westheim A. A comparison of the two beta-blockers carvedilol and atenolol on left ventricular ejection fraction and clinical endpoints after myocardial infarction. a single-centre, randomized study of 232 patients. Cardiology 2005; 103:148-155.
41. Gao F, Chen J, Lopez BL, Christopher TA, Gu J, Lysko P, et al. Comparison of bisoprolol and carvedilol cardioprotection in a rabbit ischemia and reperfusion model. Eur J Pharmacol 2000; 406:109-116.

42. Hjalmarson A. Cardioprotection with beta-adrenoceptor blockers. Does lipophilicity matter? Basic Res Cardiol 2000; 95 Suppl 1:141-45.

43. Kopecky SL. Effect of beta blockers, particularly carvedilol, on reducing the risk of events after acute myocardial infarction. Am J Cardiol 2006; 98:1115-1119.

44. Fonarow GC. Role of carvedilol controlled-release in cardiovascular disease. Expert Rev Cardiovasc Ther 2009; 7:483498.

45. DiNicolantonio JJ, Lavie CJ, Fares $H$, Menezes AR, O'Keefe JH. Meta-analysis of carvedilol versus beta 1 selective beta-blockers (atenolol, bisoprolol, metoprolol, and nebivolol). Am J Cardiol 2013; 111:765-769.

46. Lin TT, Arnold Chan K, Chen HM, Lai CL, Lai MS. Class effect of beta-blockers in survivors of ST-elevation myocardial infarction: A nationwide cohort study using an insurance claims database. Sci Rep 2015; 5:13692.

47. Bugiardini R, Cenko E, Ricci B, Vasiljevic Z, Dorobantu M, Kedev $S$, et al. Comparison of early versus delayed oral beta blockers in acute coronary syndromes and effect on outcomes. The American journal of cardiology. 2016; 117:760-767.

\section{Publish in International Archives of Medicine}

International Archives of Medicine is an open access journal publishing articles encompassing all aspects of medical science and clinical practice. IAM is considered a megajournal with independent sections on all areas of medicine. IAM is a really international journal with authors and board members from all around the world. The journal is widely indexed and classified Q1 in category Medicine. 